\title{
Decrease of electromyographic activity of concave paraspinal muscles in scoliotic girls after specific soft tissue therapy Marianna Białek ${ }^{1}$, Wiesław Chwała ${ }^{2}$, Tomasz Kotwicki*3 and Andrzej M'hango ${ }^{3}$
}

\author{
Address: ${ }^{1}$ BMK Functional Therapy, Wroclaw, Poland, 2 Department of Biomechanics, Laboratory of Biokinetics, Academy of Physical Education, \\ Cracow, Poland and ${ }^{3}$ Department of Pediatric Orthopedics and Traumatology, University of Medical Sciences, Poznan, Poland \\ Email: Tomasz Kotwicki* - kotwicki@amp.edu.pl \\ * Corresponding author
}

from 4th International Conference on Conservative Management of Spinal Deformities

Boston, MA, USA. 13-16 May 2007

Published: 12 October 2007

Scoliosis 2007, 2(Suppl I):SI doi:I0.1I86/I748-7|6I-2-SI-SI

This abstract is available from: http://www.scoliosisjournal.com/content/2/SI/SI

(C) 2007 Białek et al; licensee BioMed Central Ltd.

\section{Objective}

Progressive idiopathic scoliosis (IS) causes contractures and shortening in the paraspinal soft tissues. Soft tissue related impediments to scoliosis correction may be addressed by a specific physiotherapy. It is assumed that paraspinal concave muscles which develop their action along the chord of the curvature, may promote curve increase. The hypothesis was that specific soft tissue therapy is able to interfere with the concave side muscle activity. The objective of the study was to compare the bioelectrical activity of convex and concave paraspinal muscles at the apex of the curve, before and after specific soft tissue therapy.

\section{Study design}

Evaluation of surface electromyographic (EMG) records was performed in fifteen consecutive female subjects with IS. They were $14.0 \pm 1.6$ years of age, presenting a structural single thoraco-lumbar adolescent IS with Cobb angle $29.7 \pm 7.2$ degrees and $9.5 \pm 1.6$ degrees of Bunnell angle of trunk rotation [1]. Paraspinal muscle activity at rest was measured, at the convex and concave side of the spine in prone position and in relaxed sitting position, both before and after a single 60-minute session of specific soft tissue therapy. Bioelectrical activity of the muscles was calculated as the area of the surface beneath the integrated EMG curve (plot of voltage versus time).

\section{Results}

Convex side paraspinal muscle activity revealed higher values than that of the concave side at each position. The difference in convex versus concave was not significant in the prone position ( $\mathrm{p}>0.05)$, but was highly significant in the sitting position $(\mathrm{p}<0.001)$. Soft tissue therapy decreased muscle activity at both sides of the spine. The difference was significant at the concave side in the sitting position ( $\mathrm{p}=0.021)$ and in the prone position $(\mathrm{p}=$ 0.029 ), but was not significant on the convex side ( $\mathrm{p}>$ $0.05)$. After therapy the convex to concave ratio decreased from the mean value of 1.66 to the mean value of 1.20. The difference was not significant $(\mathrm{p}=0.32)$.

\section{Conclusion}

A single session of specific soft tissue therapy decreased the bioelectrical activity of the paraspinal back muscles at the concave side of thoraco-lumbar scoliosis.

\section{References}

I. Bunnell WP: An objective criterion for scoliosis screening. J Bone Joint Surg 1984, 66A:I38I-I387. 